\title{
Innovations
}

\section{Informing voluntary patients of their rights}

\author{
Philip Sugarman, Senior Registrar in Forensic Psychiatry; and Angela Long, Clinical \\ Records Officer, Reaside Clinic, Bristol Road South, Birmingham B45 9BE
}

Informal patients have the common law right to refuse treatment, and to leave hospital. We have designed a leaflet for the needs of informal patients on admission, and of those whose "section" has lapsed. Other hospitals may wish to offer a similar service, and are free to amend and use the leaflet shown.

Name

Your hospital doctor is

Date of admission

(or first informal status)

\section{YOUR RIGHTS}

\section{AS A VOLUNTARY PATIENT}

You are in hospital on the advice of your doctor. You have the same rights as any patient in an ordinary hospital.

\section{If you want to leave}

You are a voluntary patient, and you are not being held against your will. If you wish to leave hospital, you should talk to a member of staff, such as your key-worker or doctor.

You have the right to insist on leaving hospital. You will then be allowed to leave, unless there is a good reason to keep you, under the Mental Health Act.

If you came to hospital from court or prison, you may have to return there. Your doctor or key-worker can explain this to you. If you have a solicitor or probation officer, they can also advise you about this.

\section{Your treatment}

Your doctor will talk to you about the treatment he/ she thinks you need. You may well accept his advice. However, you are a voluntary patient. This means that you cannot be given any treatment against your will, except in an emergency.

\section{Your letters}

You can send letters to anyone, and you can recieve letters from anyone. The hospital does not have the right to stop your letters. You can send as many letters as you want.

\section{If you have any questions or complaints}

If you want to ask something, or to complain about something, talk to your key-worker, doctor or social worker. If you are not happy you may write to the hospital managers. Send your letter to:

The Clinical Records Officer, Reaside Clinic.

If you are still not happy with the reply you are given you can ask the Mental Health Act Commission to help you. You can also write to the Commission even after you have left hospital.

\section{Mental Health Act Commission}

The Commission was set up especially to make sure that mental health law is used properly and that patients are cared for properly while they are in hospital. They make frequent visits to this Clinic. You can ask them to help you by writing to them at:

The Mental Health Act Commission

Maid Marian House, 56 Houndsgate, Nottingham, NG1 6BG

\section{Your nearest relative}

A copy of these notes can be sent to your nearest relative who we have been told is:

If you wish this to happen please tell your key-worker or doctor.

If there is anything you do not understand, ask your key-worker, doctor or social worker. If you need help in writing a letter, you should ask one of them, or a relative or friend. 